\title{
Goldilocks and the licensing firm: Choosing a partner when rivals are heterogeneous*
}

\author{
Anthony Creane ${ }^{\dagger}$ and Hideo Konishi ${ }^{\ddagger}$
}

We consider how the amount of the technology transferred and the characteristics of the partner affect licensing. We find that a partial technology transfer can be the joint-profit minimizing transfer, though under weakly concave demand, a complete transfer always increases joint profit if there are at least three firms. We establish a "Goldilocks" condition in partner selection: the optimal licensee is neither too efficient nor too inefficient. Profitable transfers between sufficiently inefficient firms reduce welfare, though a transfer from a sufficiently efficient firm increases welfare. When making a complete transfer the efficient firm tends to select an insufficiently inefficient partner.

JEL:D4, L24, L4

Key words: licensing, technology transfers

${ }^{\dagger}$ Michigan State University

*Boston College

*We thank Jay Pil Choi, Carl Davidson and Thomas Jeitschko, as well as participants of the Michigan State theory seminar, for their comments on a preliminary draft of this paper. Of course, all errors are our own. 


\section{Introduction}

Knowledge and technical know-how is transferred between firms in many ways: through licensing, acquisition of rivals, joint ventures, etc. ${ }^{1}$ For example, in the auto market, the joint production venture between GM and Toyota (NUMMI) was partly motivated by giving GM the opportunity to learn "Toyota's efficient manufacturing and management methods, and to apply these techniques to other GM facilities" (Fenton 2005). ${ }^{2}$ An intriguing aspect of the GM-Toyota joint venture is that Toyota actually was initially in discussion with Ford before settling on GM (The Washington Post 1980). This leads to the question of why Toyota picked GM over Ford, or over Chrysler for that matter - three non-homogenous companies. An obvious answer is that GM was the profit-maximizing partner. This raises the issue of what are the characteristics of the optimal partner among a heterogeneous group when transferring technology through joint ventures or licensing. ${ }^{3}$ For example, was Toyota choosing the least efficient among the three? On the other hand, since in this case the Federal Trade Commission (FTC) would determine whether the joint venture was allowed, would have Ford or Chrysler or no one been a better partner in terms of welfare? More generally, when approving licensing agreements would competition authorities want to influence the partner chosen, i.e., does the welfare maximizing partner differ from the profit maximizing one?

A second intriguing aspect of this case is that GM's costs have decreased since, but have never matched Toyota's. In this sense, the transfer of Toyota's know-how was not complete, and many might suspect it could never have been. This raises the issue of whether Toyota wanted to control the amount of knowledge transferred to GM - could GM becoming more efficient harm Toyota on the margin more than it benefited GM? ${ }^{4}$ Likewise, when licensing a technology to a rival the licensor can control what technology is licensed. This issue also plays a

\footnotetext{
${ }^{1}$ A joint venture is viewed as a mechanism to transfer knowledge that cannot be done via licensing (Kogut 1988).

2 Such cost improvements through learning the rival's knowledge were also a motivating factor in Ford's long term partnership with Mazda (Levin 1992) as well as in many other industries from similar joint ventures in the steel industry (Cohen 1990) to Sony's conscious strategy (Inkpen 2000), as joint ventures are viewed as mechanisms to transfer technology (Kogut 1988).

${ }^{3}$ Like the costs with joint ventures, the costs of licensing technology are often quite high, limiting the number of potential partners. For example, Teece (1976) finds that the costs associated with technology transfers with licensing to be on average $19 \%$ and as much as $59 \%$ of total costs. Caves', et al. (1983) find that "[t]he preparation and contract costs involved in transferring technology are not trivial, and they strongly qualify the public good character that economists assign to technology transfer." Astebro (2002) also finds evidence that such costs have real effects on the decision to adopt a technological innovation.

${ }^{4}$ See Roehl and Truitt (1987) for examples of the knowledge transferred being controlled in joint ventures.
} 
role in the initial question as the amount of technology that can be transferred could affect the choice of partner or whether an agreement could be reached. These too are all issues that would concern a welfare-maximizing competition authority when approving licensing agreements. Though one might have expected that all of these questions would have already been examined in the well-developed licensing literature, surprisingly they have not for the most part, as the majority of work has been restricted to analyzing complete transfers in duopolies or with homogenous rivals, and often assuming linear demand. ${ }^{5}$

In this paper we analyze a market with heterogeneous firms to determine which rival would a firm choose to license its knowledge or technology, how much would it choose to license, how limits in its ability to transfer the knowledge affects its decision, and the welfare implications of these choices. Specifically, the firms compete in Cournot competition and differ in their constant marginal cost of production and so a technology transfer reduces a firm's marginal cost. We assume that the production decisions of the firms remain independent with any agreement. That is, we focus on the direct gains from the licensing and so abstract from any possible benefits from collusion, especially since outside of a duopoly, pair-wise collusion is not profitable in Cournot competition (Salant et al. 1983). Furthermore, competition authorities typically impose conditions when approving technology agreements so as to prevent collusion from occurring.

We begin by analyzing the effects of a partial transfer between two firms. We find that under weakly concave demand if the licensee is sufficiently inefficient then a small technology transfer reduces the joint profit of the two firms (Proposition 3). ${ }^{6}$ Thus, we do not expect to see partial technology transfers to have marginal firms as licensees. In their seminal paper Katz and

\footnotetext{
${ }^{5}$ With respect to the amount transferred, the seminal work by Katz and Shapiro (1985), as well as Rockett (1991) and Choi (2002), consider this but in a duopoly. In the latter two, the focus is on the licensee using the technology to imitate or innovate in the future. With respect to heterogeneous rivals, Rockett (1990) considers which of two potential entrants an incumbent would license so as to deter entry, which does do not play a role in our model. Hernandez-Murillo and Llobet (2006) also consider heterogeneity, but since the monopolist-competitive model of Dixit and Stiglitz is used each potential licensee is a monopolist. With respect to linear demand, the seminal work by Katz and Shapiro (1985), Katz and Shapiro (1986) and Kamien et al. (1992) are exceptions to this assumption, as well as more recently Giebe and Wolfstetter (2007) and Farrell and Shapiro (2008) though all have homogenous potential licensees. The middle three focus on optimal licensing (auction) strategies, while the latter focuses on the welfare effects of potentially invalid patents. For a review of the literature see Sen and Tauman (2007).

6 This also has an interesting implication regarding the "merger paradox" (i.e., that mergers are usually unprofitable): two firms could have a profitable merger under conditions that normally yield unprofitable mergers (Salant et al. 1983) by having the less efficient firm become even less efficient and leaving the firms as independent divisions (Baye et al. 1996).
} 
Shapiro (1985) have shown that licensing could reduce joint profit in a duopoly if the licensor effectively has a monopoly because then any transfer would reduce the licensor's near monopoly profit and hence joint profit. ${ }^{7}$ In contrast, our result holds for non-duopoly markets and the licensor need not have a near monopoly position (in fact, it could be rather inefficient).

Given our result that small transfers can be unprofitable, we then turn to see if any general conclusions can be made regarding complete technology transfers (i.e., the transferee's cost equals the transferor's cost). Surprisingly, under the assumption of weakly concave demand we are able to show that licensing that involves a complete technology transfer is always profitable so long as there are at least three firms in the market (proposition 4). Thus, as long as the transfers is complete (and we have an interior condition), a technology transfer is always profitable no matter its absolute size.

Specializing to linear demand we are able to derive the range over which profit is decreasing in the amount of the technology transferred and the range over which the technology transfer is unprofitable, finding that this range can be up to eighty percent of the cost differences between the firms. Thus, a license to an inefficient firm may need to make the licensee nearly as efficient as the licensor for it to be profitable. An implication of this is that an attempted technology transfer that is risky, i.e., either transfers all of the technology or, with some probability, transfers nothing, can be more profitable than one that transfers a fraction of the technology with certainty, even when this fraction is greater than the expected amount transferred in the risky case.

We then focus on which partner would maximize joint profit. Beginning first with complete transfers, we find that for weakly concave demand, it is neither a very inefficient nor a very efficient rival that maximizes joint profit (proposition 5) - the goldilocks condition. Intuitively, with a complete transfer the less efficient the licensee, the greater is the transfer. One might at first glance expect then that this implies that the least efficient rival must be the licensee that maximizes joint profit. This is not necessarily true because with very inefficient firms, the decrease in profit from being a little less efficient is small - profits are convex in cost - so the marginal gain from choosing a less efficient firm is small. However, the marginal cost the reduction in the market price as a result of the transfer, which harms both the licensor and the

\footnotetext{
${ }^{7}$ We show elsewhere (2009) that with more than two firms in the market that even a firm with a nearly monopoly position may license some of its technology so as to drive-out other firms.
} 
licensee - is not. So, the firm chooses a partner who is neither too efficient nor too inefficient. With instead, a transfer of a fixed amount (i.e., that causes a fixed decrease in marginal cost), the firm would choose the most efficient partner possible under strategic substitutability (proposition 6) because now the cost (the lower price) is independent of the firm chosen and a more efficient firm benefits more from a given cost reduction.

Given both the strong interest and the control that competition authorities have over licensing and technology transfers, we then consider the welfare implications of such transfers. Our first welfare result is that if both the licensor and licensee are sufficiently similar and inefficient, then profitable transfers are welfare reducing (Proposition 7). This is in contrast to Katz and Shapiro (1985) who found that profitable transfers are never welfare reducing in a duopoly, hence, the importance of considering non-duopoly markets. This is also in contrast to Katz and Shapiro (1986) and Sen and Tauman (2007) who find that with homogenous firms, licensing always raises welfare and so heterogeneity is also important in evaluating the welfare implications of licensing. ${ }^{8}$ The policy inference is that it may be better to discourage licensing between inefficient firms. On the other hand, we are also able to obtain a condition for transfers to be welfare increasing. Specifically, when the most efficient firm makes a complete transfer, then social welfare always increases under general demand (proposition 10).

We are able to obtain further welfare results by assuming linear demand. First, if the licensor has above average marginal cost, then if a small technology transfer reduces joint profit, it reduces welfare (proposition 8). ${ }^{9}$ Second, if the licensor is sufficiently efficient then there are welfare increasing transfers that reduce joint profit. ${ }^{10}$ Third, we show that for complete transfers, if the licensor is sufficiently efficient, then it would choose a more efficient partner than the one that would maximize welfare (proposition 9), which can be generalized to downward sloping demand (proposition 9'). The conclusion for a policy maker whose objective is to maximize social welfare is that efficient firms should not be discouraged from licensing their technology nor restricted in the amount of technology they transfer, and if a complete

\footnotetext{
${ }^{8}$ Faulí-Oller and Sandonís (2002) have shown that in a duopoly with price competition, licensing by means of a royalty could reduce welfare because, as they put it, "the royalty works as a collusive device."

${ }^{9}$ With respect to the "merger paradox," under these conditions firms that choose the strategy of merging and raising a division's cost to increase joint profits will actually increase welfare.

${ }^{10}$ Katz and Shapiro (1985) also find this is possible, but there it requires that the less efficient firm is not currently producing and only would produce with the technology transfer.
} 
transfer is possible, the efficient firm should be encouraged to pick less efficient partners.

In the next section we introduce the basic modeling assumptions. Section 3 examines the effect the amount of technology transferred has on profit while section 4 examines the effect of the type of partner. Section 5 contains the welfare analysis and section 6 concludes.

\section{The Model}

We consider the basic Cournot market structure. There is a commodity besides a numeraire good, and its inverse demand function is $P(Q)$ which has $P^{\prime}(Q)<0$ for all $Q \in[0, \bar{Q}]$. There are $K$ firms in the market with no fixed cost of production and we will consider only equilibria in which all $K$ firms remain active, i.e., the licensing is not potentially drastic.

Firms differ in their constant marginal cost $c_{k}$, and firms $1,2,3 \ldots \in K$ are ordered in such a way that $c_{1} \leq c_{2} \leq c_{3} \leq \ldots$ Firms are indexed as $k \in\{1,2, \ldots, K\}$ with $k=1$ being the most efficient firm. With a little abuse of notation let the set $\{1,2, \ldots, K\}$ be denoted by $K$.

Each firm $k$ 's production level is denoted by $q_{k}$. Firm $i$ 's profit function is written as:

$$
\pi_{i}\left(q_{i}, Q_{-i}\right)=\left(P(Q)-c_{i}\right) q_{i}
$$

where $Q=\sum_{k=1}^{K} q_{k}$. The first order condition for profit maximization (assuming interior solution) is

$$
P^{\prime}(Q) q_{i}+P(Q)-c_{i}=0
$$

This implies

$$
q_{i}=\frac{\left(P(Q)-c_{i}\right)}{-P^{\prime}(Q)}
$$

Thus, firm $i$ 's profit is written as

$$
\pi_{i}=\frac{\left(P(Q)-c_{i}\right)^{2}}{-P^{\prime}(Q)} .
$$

We assume the strategic substitute condition throughout the paper: for all $i \in K$

$$
P^{\prime \prime}(Q) q_{i}+P^{\prime}(Q) \leq 0
$$


This condition guarantees the uniqueness of equilibrium of this game. Finally, let $C=\sum_{k=1}^{K} c_{k}$ denote the aggregate marginal cost. With this we can establish a standard result, whose derivation will be useful for later analysis.

Lemma 1. Under the strategic substitute condition, equilibrium is unique. Moreover, equilibrium total output level $Q$ is a decreasing function of aggregate marginal cost $C$.

Proof. Since equilibrium $q_{i}$ 's are expressed only by the equilibrium total output level $Q$, if we can show that $Q$ is unique, then we are done. Summing the strategic substitute conditions up over all firms (2), we obtain

$$
P^{\prime \prime}(Q) Q+K P^{\prime}(Q) \leq 0
$$

Equilibrium total output level $Q$ is determined by the sum of the first order conditions (1):

$$
P^{\prime}(Q) Q+K P(Q)-C=0
$$

Differentiating the LHS of (3) with respect to $Q$ produces,

$$
\frac{D(L H S)}{d Q}=P^{\prime \prime}(Q) Q+(K+1) P^{\prime}(Q)=P^{\prime \prime}(Q) Q+K P^{\prime}(Q)+P^{\prime}(Q)<0 .
$$

From (3), then it follows that aggregate output is decreasing in C.//

\section{Production Technologies and Transferability}

Each firm $i$ has its own technology of producing the commodity (the marginal cost of production is $c_{i}$ ), and it has the property right to its own technology (e.g., it holds a patent). Thus, firm $i$ can sell it or some fraction of its technology (with an exclusive usage agreement), denoted $T$, to another firm through a licensing or a joint production agreement. As discussed in the introduction, the real world instances that motivate our study lead us to focus on pair-wise agreements and to assume that the output decisions remain independent after any transfer as the independence of production decisions is usually a condition imposed by competition authorities (and collusion is profit-reducing in the Cournot setting). 
We can imagine a situation where technologies that firms $i$ and $j$ own have complementarities (and in some cases, incompatibilities: nonsynergy case), but we assume that technologies are independent so as to focus on the pure effects of licensing. That is, if firms $i$ and $j$ have technologies with marginal $\operatorname{costs} c_{i}$ and $c_{j}$, respectively (assume $c_{i}<c_{j}$ without loss of generality), then firm $j$ 's technology is worthless for firm $i$, while firm $j$ can reduce its marginal cost of production by $T \in\left(0, c_{i}-c_{j}\right]$ by adopting firm $i$ 's technology through licensing or some agreement. That is, after the (partial) technology transfer, firm $j$ 's marginal cost is $c_{j}-T \geq c_{i}$.

\subsection{Partial Technology Transfers}

Following previous work (e.g., Katz and Shapiro 1985), we focus on how technology transfers affect the joint profit of firms $i$ and $j$. By the technology transfer, firm $j$ 's marginal cost decreases. This reduces $C$ (aggregate marginal cost), and there will be negative externalities to other firms through the lower price since $K$ is fixed. The sum of profit for firms $i$ and $j$ is

$$
\Pi=\pi_{i}+\pi_{j}=\frac{\left(P(Q)-c_{i}\right)^{2}}{-P^{\prime}(Q)}+\frac{\left(P(Q)-c_{j}\right)^{2}}{-P^{\prime}(Q)} .
$$

Recalling that $c_{i}<c_{j}$, and treating $T$ as a continuous variable (the amount of technology that is transferred from $i$ to $j$ ), that is, the cost reduction for firm $j$ can be made continuously, it is easy to see from (3) that the equilibrium given a transfer $T$ is determined by

$$
P^{\prime}(Q(T)) Q(T)+K P(Q(T))-(C-T)=0
$$

Totally differentiating this equation, we obtain

$$
\frac{d Q}{d T}=\frac{1}{-P^{\prime \prime} Q-(K+1) P^{\prime}}>0 .
$$

Thus, the change in joint profit from a small transfer (i.e., evaluated at $T=0$ ) is: 


$$
\begin{gathered}
\frac{d \Pi}{d T}=\frac{-2\left(P-c_{i}\right)\left(-P^{\prime}\right)^{2}+\left(P-c_{i}\right)^{2} P^{\prime \prime}-2\left(P-c_{j}\right)\left(-P^{\prime}\right)^{2}+\left(P-c_{j}\right)^{2} P^{\prime \prime}}{\left(-P^{\prime}\right)^{2}\left(-P^{\prime \prime} Q-(K+1) P^{\prime}\right)}+\frac{2\left(P-c_{j}\right)}{-P^{\prime}} \\
=\frac{1}{\left(-P^{\prime}\right)^{2}\left(-P^{\prime \prime} Q-(K+1) P^{\prime}\right)}\left[-2\left(P-c_{i}\right)\left(-P^{\prime}\right)^{2}+\left(P-c_{i}\right)^{2} P^{\prime \prime}+\left(P-c_{j}\right)^{2} P^{\prime \prime}\right. \\
\left.-2 P^{\prime}\left(P-c_{j}\right)\left(P^{\prime}-P^{\prime \prime} Q-(K+1) P^{\prime}\right)\right] \\
=\frac{1}{-P^{\prime \prime} Q-(K+1) P^{\prime}}\left[-2\left(P-c_{i}\right)+2 K\left(P-c_{j}\right)\right. \\
\left.\quad+\left[\left(P-c_{i}\right)^{2}+\left(P-c_{j}\right)^{2}+2\left(P-c_{j}\right)\left(P^{\prime} Q\right)\right] \frac{P^{\prime \prime}}{\left(-P^{\prime}\right)^{2}}\right]
\end{gathered}
$$

Since the sign of the denominator is positive, if the sign of the numerator is positive, then we can say that joint profit increases as technology transfer $T$ increases. We summarize this as a lemma.

Lemma 2. A marginal technology transfer from firm $k$ to firm $j$ improves their joint profit if and only if the following condition holds.

$$
2\left[-\left(P-c_{i}\right)+K\left(P-c_{j}\right)\right]+\left[\left(P-c_{i}\right)^{2}+\left(P-c_{j}\right)^{2}+2\left(P-c_{j}\right)\left(P^{\prime} Q\right)\right] \frac{P^{\prime \prime}}{\left(-P^{\prime}\right)^{2}}>0 .
$$

Surprisingly, the marginal impact of a technology transfer on joint profit need not be positive. First, it is affected by the concavity of demand, i.e., the sign of $P^{\prime \prime}$. Further, the contents of the first and second brackets can also take either sign. Potentially, then, the marginal technology transfer could reduce joint profit or more importantly the entire technology transfer may reduce joint profit. Since the first bracketed term can take either sign, even if demand is linear $\left(P^{\prime \prime}(Q)=0\right)$, the above condition can be violated - that is, the marginal impact of the technology transfer on joint profit can be negative. As linear demand is a standard assumption in the licensing literature (see the discussion in the introduction), it is natural to begin with this case when determining conditions for technology transfers to reduce joint profit and then consider the more general case.

From lemma 2, with linear demand the condition for the marginal transfer to increase joint profit is $-\left(P-c_{i}\right)+K\left(P-c_{j}\right)>0$. We can rearrange this to the more intuitive condition that firm $j$ 's profit margin is not too small relative to the cost difference between the two firms: 


$$
P-c_{j} \geq \frac{c_{j}-c_{i}}{K-1} .
$$

However, as $P$ is a function of $c_{j}$, which depends on $T$, potentially this condition may not hold for large T. Fortunately, it is straightforward to check that the aggregation of the strategic substitute conditions implies that if the condition holds at the initial $\operatorname{costs} c_{i}$ and $c_{j}$ then it holds at all levels of technology transfers $T \in\left(0, c_{i}-c_{j}\right]$ (i.e., $\left.d P / d c_{k} \leq 1\right)$. In this case, joint profit as a function of the amount transferred takes its minimum value at $T=0$, and is monotonically increasing. To summarize,

Proposition 1: With linear demand, joint profit of firms $i$ and $j, \pi_{i}^{T}+\pi_{j}^{T}$, increases monotonically with $T \in\left(0, c_{i}-c_{j}\right]$, if and only if the following condition is satisfied,

$$
P-c_{j} \geq \frac{c_{j}-c_{i}}{K-1}
$$

It immediately follows from this proposition that for the firms, it is optimal to set the transfer level at the maximum $T=c_{i}-c_{j}$ when the condition holds.

Inspection reveals that the condition is more likely to hold the more firms that are in the market $(K)$, the more similar are the firms $\left(c_{j} \rightarrow c_{i}\right)$ and the more efficient is firm $j\left(P-c_{j}\right.$ is large). All three turn on the harm the technology transfer causes by reducing the market price versus the benefit to the receiving firm from having lower costs (greater output). First, as there are more firms in the market $(K)$, for a given increase in firm $j$ 's output (the benefit to joint profit), the harm is spread across more firms - the other firms produce less, the "business stealing" effect - and so less harm to firm $i$. Second, the more similar are the firms, the smaller the maximum transfers and hence maximum harm (since the condition holds for all $T$ ). Finally, when firm $j$ is sufficiently inefficient a small technology transfer creates little benefit since its output is close to zero (in other words, profit is convex in cost). That is, the larger the price-cost difference $\left(P-c_{j}\right)$, the greater the benefit to the licensee from receiving a small transfer.

In the seminal work by Katz and Shapiro (1985) it was shown that in a duopoly setting an arbitrarily small technology transfer is jointly profitable when the aggregation of the strategic substitute condition holds and if the firms are sufficiently similar in cost. We see that with linear 
demand any size of transfer (up to making the firms equally efficient) can be profitable when our condition holds. Further, the condition holds in non-duopoly settings and the firms need not be sufficiently similar in cost so long as either there are a large number of rivals or the licensee is sufficiently efficient ( $P$ sufficiently greater than $c_{j}$ ). At the end of this subsection we show how our proposition generalizes to weakly concave demand (which implies that the strategic substitute condition holds).

Potentially more interesting is the case when the condition is violated and a small technology transfer reduces joint profit. That is, if firm $i$ chooses a very inferior partner (or only inferior partners are available) so that $c_{j}-c_{i}$ is large or $P-c_{j}$ is small, then a small transfer would decrease joint profit and possibly even a complete transfer would decrease joint profit. That is, no transfer would be optimal. To determine the range of $T$ such that transfers are unprofitable, we first solve for the equilibrium price, quantities and profit with linear demand.

Normalizing the intercept and slope (which does not affect the results) to one, with linear demand we have $P(Q)=1-Q$. Assuming further that constant marginal cost $c_{k} \in(0,1)$ and letting $Q(C)$ denote the initial equilibrium output given starting aggregate marginal cost $C$ from (3) we have

$$
\begin{aligned}
& Q(C)=\frac{K}{K+1}-\frac{C}{K+1} \\
& P(C)=1-\frac{K}{K+1}+\frac{C}{K+1}=\frac{1+C}{K+1} \\
& q_{k}(C)=\frac{1}{K+1}+\frac{C}{K+1}-c_{k} .
\end{aligned}
$$

Therefore, with linear demand joint profit before licensing is

$$
\pi_{i}+\pi_{j}=\left(\frac{1}{K+1}+\frac{C(K)}{K+1}-c_{i}\right)^{2}+\left(\frac{1}{K+1}+\frac{C(K)}{K+1}-c_{j}\right)^{2} .
$$

Joint profit after the licensing given $T \in\left(0, c_{i}-c_{j}\right]$ is

$$
\begin{aligned}
& \pi_{i}^{T}+\pi_{j}^{T} \\
& =\left(\frac{1}{K+1}+\frac{C-T}{K+1}-c_{i}\right)^{2}+\left(\frac{1}{K+1}+\frac{C-T}{K+1}-\left(c_{j}-T\right)\right)^{2} \\
& =\left(P(C)-c_{i}-\frac{T}{K+1}\right)^{2}+\left(P(C)-c_{j}+T-\frac{T}{K+1}\right)^{2},
\end{aligned}
$$


where the $T$ superscript indicates a transfer has occurred. Thus, the total benefits from the technology transfer is

$$
\begin{aligned}
\Delta \pi^{T} & =\pi_{i}^{T}+\pi_{j}^{T}-\pi_{i}-\pi_{j} \\
& =\left(P(C)-c_{i}-\frac{T}{K+1}\right)^{2}-\left(P(C)-c_{i}\right)^{2}+\left(P(C)-c_{j}+T-\frac{T}{K+1}\right)^{2}-\left(P(C)-c_{j}\right)^{2} \\
& =\frac{\left(K^{2}+1\right) T^{2}}{(K+1)^{2}}+\frac{2 T}{K+1}\left[(K-1)\left(P(C)-c_{j}\right)-\left(c_{j}-c_{i}\right)\right] .
\end{aligned}
$$

With these preliminary calculations we can obtain the following proposition (the proof is in the appendix).

Proposition 2. With linear demand, the joint profit of firms $k$ and $j$ initially decreases monotonically for $T \in(0, \underline{T})$ and then increases monotonically for $T \in\left(\underline{T}, c_{j}-c_{k}\right]$, if the following condition is satisfied

$$
P(C)-c_{j}<\frac{c_{j}-c_{k}}{K-1} .
$$

This implies that there is a critical value $T^{*}>\underline{T}$, such that the total benefit from the transfer, $\Delta \pi^{T}$, takes negative values for $T \in\left(0, T^{*}\right)$.

Since joint profit is convex with respect to $T$, then if the firms are considering licensing, the joint profit maximizing level of transfers will either be all or nothing. Thus, if firm $i$ cannot make a complete transfer to firm $j$, specifically, if the maximum technology that it could transfer $T<T^{*}$, then a licensing agreement will not be reached between the two firms.

An example may help clarify the effects here.

Example 1. Consider a market with three firms $(K=3)$, with technologies $c_{1}=0, c_{2}=.2$ and $c_{3}$ $=.4$. In a licensing agreement between firm 1 and firm $3, \underline{T} \approx .16$, that is, a technology transfer that only successfully transferred forty percent of the superior firm's technology advantage would maximize the loss between the two firms. Indeed, to make such a transfer profitable would require an eighty percent of the technology advantage to be transferred (an eighty percent 
cost reduction for firm 3). As the cost differences between firms is usually a multifaceted affair (consider Toyota and GM), a more efficient firm may not be able to transfer the entire cost superiority, and so this could well be a binding constraint. If instead firm 3's cost lie anywhere between .24 and .4 , then a small transfer to firm 3 reduces joint profit; a licensing agreement would not be reached. Interestingly, the same relative relationship holds between firm 2 and 3: for a technology transfer to be profitable requires at least eighty percent of the technology difference to be transferred. Finally, if firm 2 were more inefficient $\left(c_{2} \geq .29\right)$ then a small technology transfer between firm 1 and 2 would also reduce joint profit. In this case, if only a small amount of the technology were transferable, the most efficient firm would not engage in a technology transfer.//

These results are also related to Katz and Shapiro (1985) who find that in a duopoly joint profit decreases with a technology transfer if the efficient firm's monopoly price is arbitrarily close to the inefficient firm's marginal cost. That is, when the firms are sufficiently different in cost so that before the transfer the efficient firm nearly drives out its rival. In this case, the efficient firm loses its near monopoly position with any transfer and so any transfer is jointly unprofitable. $^{11}$ Here we see from proposition 2 and example 1 that with linear demand unprofitable transfers can occur in non-duopoly markets and further that there are new and different conditions under which a technology transfer reduces joint profit. Specifically, the licensor need not have a near monopoly position nor even be the most efficient firm (it could even be the second most inefficient firm). First, the licensor can be very inefficient and a small transfer is still jointly unprofitable when $c_{j}$ is sufficiently close to $P(C)$. Second, the licensee's cost can be significantly less than the market price and a small transfer is still jointly unprofitable when the two firms are sufficiently different in cost. At the end of this subsection we show that the former condition ( $c_{j}$ is sufficiently close to $P(C)$ ) can be extended to weakly concave demand.

A different implication of proposition 2 is that under this condition the firms jointly benefit if they, instead of actually transferring the technology, can raise firm $j$ 's cost. This has an interesting implication regarding the "merger paradox" (that in Cournot settings mergers

\footnotetext{
${ }^{11}$ Creane and Konishi (2009) show that with more than two firms, licensing by a firm with a near monopoly position can be profitable (in contrast to Katz and Shapiro 1985) when it drives other firms out of the market.
} 
without large cost synergies are not profitable, see Salant et. al 1983). Specifically, if the two firms merge, but keep their production decisions independent (see, e.g., Kamien and Zang 1990) and have firm $j$ 's cost increase, then the merger becomes profitable. Raising a division's cost would seem to almost always be feasible.

The previous example can be used to show how raising one's division's cost can make a merger profitable. Specifically, consider a market with three firms and $c_{1}=0, c_{2}=.2$ and $c_{3}=$ .24. Consider a merger between firms 1 and 3 in which they leave their output decisions of each firm (now called divisions) independent. In this case any increase in the high cost division's cost raises joint profit. More broadly, if $c_{3}>.09$, then a merger that keeps the divisions independent but raises the inefficient division's cost sufficiently raises joint profit.

We bring to a close this subsection by considering what conclusions we can arrive to under more general demand. Propositions 1 and 2 partially extends to weakly concave demand case. $^{12}$ The proof of proposition 3 is found in appendix.

\section{Proposition 3: If demand is weakly concave, then}

A. when the firms have sufficiently similar costs $\left(c_{j} \approx c_{i}\right)$, a small technology transfer increases joint profit.

B. when the less efficient firm is sufficiently inefficient ( $c_{j}$ is sufficiently to close to the market price: $P(C)-c_{j} \approx 0$ ), a small technology transfer decreases joint profit.

Part B of proposition 3 indicates that we should not expect to see marginal firms (i.e., high cost/low output firms) obtaining licenses that yield only small cost improvements from their rivals. Further, if transactions cost associated with technology transfers is high (Teece 1976, Caves', et al. 1983), then even profitable transfers for more efficient firms may still yield negative net profit once the transaction cost is considered. Indeed, Astebro (2002) finds evidence that such transfer cost help to explain why technology adoption is less likely when firms have smaller plants (smaller output). Part A of proposition 3 together with part B suggests that the licensing of small innovations is more likely to be observed between similar firms -

\footnotetext{
${ }^{12}$ Case A of Proposition 3 corresponds to the last part of convex function $\Delta \pi^{T}\left(c_{j} \approx c_{i}\right)$, while case B corresponds to the initial part of it (condition $P(C)-c_{j} \approx 0$ corresponds to $P(C)-c_{j}<\left(c_{j-} c_{i}\right) /(K-l)$ in linear demand case).
} 
"birds of a feather."

\subsection{Complete Technology transfers}

Propositions 2 and 3 show that a partial technology transfer from a firm to a sufficiently inefficient partner can reduce joint profit. We now consider the extent to which these results extend to complete technology transfers. Somewhat surprisingly given those results, we show that under weakly concave demand (which includes linear demand) a complete technology transfer is always profitable as long as there is a third firm. The proof is involved, and found in the appendix.

Proposition 4. Assume interior solutions (no firm chooses zero production). Then, for any pair of firms $i$ and $j$ with $c_{i}<c_{j}$, a complete technology transfer from firm $i$ to firm $j$ is joint profit improving, if $K \geq 3$ and $P^{\prime \prime}(Q) \leq 0$ for all $Q$.

This result combined with propositions 2 and 3 indicate that the only time we should expect to observe technology transfers to inefficient firms is when the transfer is complete, that is, brings the inefficient firm's cost to the licensor's level.

One thing that Proposition 4 does not state is whether a complete technology transfer is more profitable than any partial technology transfer. It appears unlikely that a partial transfer dominates a complete transfer since by proposition 3 when firm $j$ 's technology approaches firm $i$ 's, joint profit is increasing from a small transfer. In fact, it can be shown that under linear demand $\left(P^{\prime \prime}=0\right)$, a complete transfer dominates any partial transfer.

\section{Transfers of Technology and the Choice of a Partner}

While in the previous section we considered the effect that the amount of technology transferred has on joint profit given some partner, in this section we consider which partner would maximize joint profit. That is, for firm $i$, which firm $j$ would create the greatest increase in joint profit from a technology transfer? Given proposition 4 we begin by consider the case when firm 
$i$ can transfer all of its technology so that its partner's cost equals its cost ex post (or equivalently the amount transfer is a constant fraction of the cost difference). That is, when $T=c_{j}-c_{i}$, which we know will be profitable. Hence, choosing a less efficient partner leads to a larger technology transfer. We then will consider which partner would be chosen when only a fix amount of its technology can be transferred. That is, the rival's cost is reduced by the same amount regardless of the rival chosen.

\subsection{The Optimal Partner for a Complete Technology Transfer}

Recall that $Q(C)$ denotes the initial equilibrium output given starting aggregate marginal cost $C$ from (3). Therefore, let $Q\left(C^{i j}\right)$ be the equilibrium output given aggregate marginal cost $C^{i j}$ after firm $i$ makes a complete transfer to firm $j$, i.e., $C^{i j}=C-c_{j}+c_{i}$, and $T^{i j}$ denote the amount of technology transferred $\left(T=c_{j}-c_{i} \equiv T^{i j}\right)$. The total benefit (i.e., change in joint profit) from a complete technology transfer from firm $i$ to firm $j$ is

$$
\begin{aligned}
\Delta \pi^{T_{i j}} & =\pi_{i}^{T_{i j}}+\pi_{j}^{T_{i j}}-\pi_{i}-\pi_{j} \\
& =\frac{\left(P\left(Q\left(C^{i j}\right)-c_{i}\right)^{2}\right.}{-P^{\prime}\left(Q\left(C^{i j}\right)\right)}+\frac{\left(P\left(Q\left(C^{i j}\right)\right)-c_{i}\right)^{2}}{-P^{\prime}\left(Q\left(C^{i j}\right)\right)}-\frac{\left(P(Q)-c_{i}\right)^{2}}{-P^{\prime}(Q)}-\frac{\left(P(Q)-c_{j}\right)^{2}}{-P^{\prime}(Q)} .
\end{aligned}
$$

Let us consider which partner $j$ would maximize joint profit from a transfer of technology from firm $i$. Noting that $d C^{i j} / d c_{j}=-1$ (selecting a less efficient firm decreases aggregate cost after the transfer), so $d Q\left(C^{i j}\right) / d c_{j}=-d Q / d C \equiv\left[-P^{\prime \prime} Q-(K+1) P^{\prime}\right]^{-1}>0$, we take the derivative of $\Delta \pi^{T_{i j}}$ with respect to $c_{j}$ :

$$
\begin{aligned}
\frac{\partial \Delta \pi^{T_{i j}}}{\partial c_{j}} & =\frac{-2\left(P\left(Q\left(C^{i j}\right)\right)-c_{i}\right)}{\left[P^{\prime}\left(Q\left(C^{i j}\right)\right)\right]^{2}} \frac{d Q}{d c_{j}}\left[2\left(P^{\prime}\left(Q\left(C^{i j}\right)\right)\right)^{2}-P^{\prime \prime}\left(Q\left(C^{i j}\right)\right)\left(P\left(Q\left(C^{i j}\right)\right)-c_{i}\right)\right]+\left[\frac{-2\left(P(Q)-c_{j}\right)}{P^{\prime}(Q)}\right] \\
& =\frac{-2\left(P\left(Q\left(C^{i j}\right)\right)-c_{i}\right)}{\left[P^{\prime}\left(Q\left(C^{i j}\right)\right)\right]^{2}} \frac{d Q}{d c_{j}}\left[2 P^{\prime}\left(Q\left(C^{i j}\right)\right)-\frac{P^{\prime \prime}\left(Q\left(C^{i j}\right)\right)\left(P\left(Q\left(C^{i j}\right)\right)-c_{i}\right)}{P^{\prime}\left(Q\left(C^{i j}\right)\right)}\right] P^{\prime}\left(Q\left(C^{i j}\right)\right)+\left[\frac{-2\left(P(Q)-c_{j}\right)}{P^{\prime}(Q)}\right] \\
& =\frac{-2\left(P\left(Q\left(C^{i j}\right)\right)-c_{i}\right)}{\left[P^{\prime}\left(Q\left(C^{i j}\right)\right)\right]^{2}} \frac{d Q}{d c_{j}}\left[2 P^{\prime}+P^{\prime \prime} q_{i}\right] P^{\prime}+\left[\frac{-2\left(P(Q)-c_{j}\right)}{P^{\prime}(Q)}\right] .
\end{aligned}
$$


Since $2 P^{\prime}+P^{\prime \prime} q_{i}<0$ by the second order condition, the first term is negative and the second term is positive. In words, the first term is the effect of a slightly more inefficient firm being selected on the licensor and licensee's profit after the licensee receives the transfer. A less efficient licensee means a greater output after the transfer which harms the licensor. Since the licensee will also have marginal $\operatorname{cost} c_{i}$ after the transfer, the licensee's profit is the same as the licensor's after the transfer. Thus, the licensee's profit after the transfer also decreases as a more inefficient firm is selected. The second term is the effect of a slightly more inefficient firm being selected on that firm's profit before the transfer. This is increasing in $c_{j}$ : a more inefficient firm has lower profit beforehand, which means a greater increase from the transfer. Interestingly, this formula says that there is (potentially) an interior optimal. The best partner is not too close to firm $i$ but not too far from firm $i$ as well. The proof is in the appendix.

Proposition 5. With a complete transfer, the joint-profit maximizing partner for a firm is neither too efficient nor too inefficient relative to the firm under weakly concave demand.

We note that for these conditions the number of rivals is fixed. ${ }^{13}$

This 'goldilocks' condition is intuitive: you cannot make a rival who is that efficient much more efficient. Thus, there is a benefit from picking less efficient rivals as there is a greater increase in profit from the transfer. However, you can pick too inefficient of a rival. The reason is that as you pick a more inefficient rival the price falls more, harming you as well as the rival. At the same time, when considering sufficiently inefficient firms, a slightly more inefficient firm does not have much less profit (since its output is approaching zero, i.e., marginal cost is approaching the price) and the gain from selecting a slightly more inefficient rival approaches zero. These trade-offs also exist if one considered instead which rival would bid the most for the complete technology transfer in a simple auction. ${ }^{14}$

\footnotetext{
${ }^{13}$ A possible variation of the partial transformation case would have the fraction of technology is proportional to the technology differences, i.e., $T(\alpha)=\alpha\left(c_{j}-c_{i}\right), \alpha \in(0,1]$. However, because the fraction is proportional, the characterization is analogous to the complete technology transfer with $\bar{c}_{j}$ now depending on $\alpha$. In this case, as $\alpha$ increases the optimal partner is always more inefficient than firm $i$ even though with complete technology transfer firm $i$ would never choose a sufficiently inefficient firm.

${ }^{14}$ In this case, since the rival does not internalize the harm to the licensee a more inefficient firm would obtain the license as compared to the rival that maximizes joint profit.
} 
If we restrict demand to be linear $\left(P^{\prime \prime}=0\right)$ then the joint profit maximizing licensor can be explicitly determined, as the derivative above then takes its peak at

$$
\begin{aligned}
c_{j} \equiv \bar{c}_{j} & =\frac{2 K c_{i}+\left(K^{2}-1\right) P(C)}{K^{2}+2 K-1} \\
& =P(C)-\frac{2 K\left(P(C)-c_{i}\right)}{(K)^{2}+2 K-1} .
\end{aligned}
$$

As an example, consider a market with four firms with costs $c_{1}=0, c_{2}=.1, c_{3}=.2$ and $c_{4}=.3$. In this case the most jointly profitable partner for the most efficient firm is to select is the intermediate cost rival (firm 3) with marginal cost $.2 .^{15}$ Interestingly, even though a small technology transfer to the least efficient rival (firm 4) would reduce joint profit, a complete transfer increases joint profit more than a transfer to the most efficient firm (firm 2).

\subsection{The Optimal Partner for Partial Technology Transfers}

We now turn to the case when firm $i$ can only make a partial transfer. Specifically, whichever partner firm $i$ selects, the partner gets exactly the same cost reduction: i.e., $T$ is common to every firm $j$. Thus, the price after transfer is independent of which firm receives the transfer and so the harm to the licensor is the same. The joint profit maximizing partner then is the one who benefits most from a cost reduction. The total benefits from licensing in this case is

$$
\begin{aligned}
\Delta \pi^{T} & =\pi_{i}^{T}+\pi_{j}^{T}-\pi_{i}-\pi_{j} \\
& =\frac{\left(P\left(Q\left(C^{T}\right)-c_{i}\right)^{2}\right.}{-P^{\prime}\left(Q\left(C^{T}\right)\right)}+\frac{\left(P\left(Q\left(C^{T}\right)\right)-c_{j}+T\right)^{2}}{-P^{\prime}\left(Q\left(C^{T}\right)\right)}-\frac{\left(P(Q)-c_{i}\right)^{2}}{-P^{\prime}(Q)}-\frac{\left(P(Q)-c_{j}\right)^{2}}{-P^{\prime}(Q)},
\end{aligned}
$$

where $C^{T}$ indicates aggregate cost after the transfer, i.e., $C^{T}=C-T$. Taking derivative with respect to $c_{j}, \Delta \pi^{T}$ monotonically decreases (see the appendix) and so we can conclude,

Proposition 6. With a fixed amount of technology to be transferred, the firm chooses the

\footnotetext{
${ }^{15}$ In this case, when firm 1 selects firm 3, the least efficient firm (4) does not produce. The example can easily be adjusted so that firm 4 does produce $\left(c_{3}=.275\right)$ in this case with no change in the qualitative results (i.e., firm .2 is still the partner that maximizes joint profit).
} 
closest partner possible under strategic substitutability.

Thus, firm $i$ would choose the closest partner (lowest cost of possible partners) if it is profitable (and if the partner is sufficiently close to firm $i$, then the transfer is guaranteed to be profitable).

Proposition 6 however allows for the possibility that there is super-additivity, that is, if $T$ $>c_{j}-c_{i}$, firm $j$ becomes more efficient than firm $i$ (or indeed firm $j$ is already more efficient than firm $i$ ). This is certainly possible if firm $j$ has some proprietorial technology that firm $i$ does not have. On the other hand, it is readily conceivable that firm $j$ does not have any special technology, in which case $T$ must be constrained so that $T \leq c_{j}-c_{i}$. Define then the most efficient firm that gets the complete amount of transfer $T$ as $c_{j}^{T}: T=c_{j}^{T}-c_{i}$. In this case, for any firm $k$ more efficient than $c_{j}^{T}\left(c_{k}<c_{j}^{T}\right)$ we are back to the realm of proposition 5 (a complete technology transfer equal to $T=c_{k}-c_{i}<c_{j}^{T}-c_{i}$ ).

\section{Welfare Effects}

We now investigate the effect of technology transfers on social welfare which we define as the sum of the firms' profit and consumer surplus. Since technology transfers reduce production cost, social welfare tends to increase in the amount of technology transferred. Indeed, Katz and Shapiro (1985) show that with a duopoly, licensing that increases joint profit always increases welfare (and welfare decreasing licensing always decreases joint profit). Likewise Sen and Tauman (2007) find licensing to be welfare improving under general licensing schemes. Here we extend the welfare analysis to when there are more than two firms and those firms are heterogeneous.

Despite previous results, we find that profitable licensing could reduce welfare. This possibility arises because if a very inefficient firm obtains a technology transfer that reduces its cost only slightly, social welfare is reduced because its resulting increase in production will displace the production of more efficient firms. This mechanism has already been noted by Lahiri and Ono (1988) who show that making a sufficiently inefficient firm more efficient reduces welfare. The question here is whether this implies that jointly profitable licensing can reduce welfare contrary to pervious results. By the use of proposition 3 combined with Lahiri 
and Ono's result we are able to show that the previous results do not generalize to when there are more than two firms and firms are heterogeneous: profitable licensing can be welfare reducing licensing.

Given this result one may wonder if there are conditions that guarantee that a technology transfer raises welfare. We then show that if the most efficient firm makes a complete technology transfer, then welfare increases. The policy implications of these results appear straightforward: competition authorities should be scrutinous of technology transfers (through licensing, joint venture, or merger) between marginal firms (in the technological efficiency sense) in an industry, especially small transfers. On the other hand, the most efficient firm within an industry should not be discourage from making a technology transfer to a rival and moreover should be encourage to make the technology transfer complete.

\subsection{Welfare-reducing profitable licensing}

To show that a profitable transfer can reduce welfare, we begin by presenting Lahiri and Ono's condition for when an improvement in the marginal cost of an inefficient firm reduces social welfare.

Lemma 3. (Lahiri and Ono 1988): When firm j's marginal cost ( $\left.c_{j}\right)$ decreases, social welfare decreases if $c_{j}$ is sufficiently high, though consumer welfare (surplus) increases.

We now combine lemma 3 with Proposition 4 to obtain a new result: there are profitable technology transfers that reduce total welfare though benefiting consumers.

Proposition 7: Suppose that demand is weakly concave and that there are more than two firms. Then, if firm $j$ has sufficiently high marginal cost $\left(c_{j}\right)$ and firm i's marginal cost is sufficiently close to firm j's, then welfare decreases though consumer welfare (surplus) increases by a profitable licensing between $i$ and $j$.

The previous example can be used to illuminate when this can happen. Recall that in that example there are four firms with costs $c_{1}=0, c_{2}=.1, c_{3}=.2$ and $c_{4}=.3$. In this case, a 
complete technology transfers between firm .2 and .3 is jointly profitable and welfare reducing. As a second example consider a market with five firms with $\operatorname{costs} c_{1}=0, c_{2}=.075, c_{3}=.15, c_{4}=$ .225 and $c_{5}=.29$ (so the least efficient firm produces in the initial equilibrium). In this case, a complete technology transfer from either firm 3 or 4 to the least efficient firm (firm 5) is jointly profitable and welfare reducing.

Though this result is novel to the licensing literature, there are previous results in the literature that may at first glance appear to be similar even though they are quite distinct. First, Katz and Shapiro (1985) have shown that in a duopoly a technology transfer can reduce welfare, but only when it reduces joint profit. Hence, such transfers would never occur. In contrast, here there can be technology transfers that reduce welfare, but increase joint profit. Second, Faulí-Oller and Sandonís (2002) have shown that in a duopoly that profitable licensing can reduce welfare, but this requires the use of a royalty (raising the recipient's marginal cost) and only occurs in price competition. As they note, "the royalty works as a collusive device" and so reduces welfare. More generally, licensing contracts can reduce welfare through their collusive effects (Shapiro 1985 and others), which do not exist here.

We have seen that technology transfers can reduce joint profit and welfare. A natural question is the relationship between these two conditions. Since welfare decreases because the harm to aggregate profit (from the efficient firms producing less) outweighs the benefit to consumers, one might suspect that when technology transfers reduce joint profit, then it reduces welfare. To obtain more explicit results, we specialize to the case of linear demand so as to use the specific condition (5) for joint profit to decrease from technology transfers. We can then obtain an explicit condition for a technology transfer to reduce welfare when demand is linear (see the appendix for the proof):

Lemma 3'. With linear demand social welfare decreases when firm j's marginal cost decreases if

$$
-\frac{2+K+3 C+2 C K}{2(K+1)^{2}}+c_{j}>0 .
$$

A sufficient condition for this is that firm $j$ has marginal cost $\left(c_{j}\right)$ greater than $\frac{1}{2 K}+C$. 
Since the market price under linear demand is $P(C)=(1+C) /(K+1)$, clearly the above condition is satisfied for relatively inefficient firms.

Now we can turn to the comparative analysis. Rewriting equation (5) - the condition for a transfer to be unprofitable - as

$$
\frac{(1+C)(K-1)}{K(K+1)}+\frac{c_{i}}{K}<c_{j}
$$

it is simple to show that if $c_{i} \geq C / K$ (i.e., above average marginal cost) then (5') implies (6) so long $K>2$; when a small technology transfer between relatively inefficient firms reduces joint profit, then it reduces welfare. To summarize:

Proposition 8: With linear demand, if a small technology transfer reduces joint profit, then it reduces welfare when the transferring firm has above average cost technology and $K>2$.

An interesting implication of this result related to the merger paradox is that if a merger between two inefficient firms that raises the less efficient division's cost is profitable, then it also raises welfare.

Perhaps more interesting is that when firm $i$ is sufficiently efficient, transfers that reduce joint profit can increase welfare. That is, even though a technology transfer would reduce joint profit it could still increase welfare. Roughly this is true when there are relatively few firms (small $K)$ or relatively high aggregate cost (large $C$ ). An example will perhaps make this clearer. Consider a market with four firms $(K=4)$ with costs $c_{1}=0, c_{2}=.15, c_{3}=.2$ and $c_{4}=.25(C=.6)$. It is straightforward to verify that a small technology transfer between the most efficient firm (firm 1) and the least efficient firm (firm 4), reduces joint profit, but increases welfare. ${ }^{16}$ This result is also suggestive technology transfers from the most efficient firm might always be welfare increasing under certain conditions. We find that the needed condition is quite simple: that the technology transfer is complete.

\footnotetext{
${ }^{16}$ The intuition behind this is as follows. If the transferring firm is relatively inefficient, then this implies all the more efficient firms are also harmed by the transfer more than the receiving firm benefits. The harm to aggregate profit is "large" (or alternatively the amount of production shift from more efficient firms to the less efficient firm is large). On the other hand, if the transferring firm is very efficient, then the harm to the other firms in the market is relatively small and so the consumer surplus benefit can outweigh the loss in aggregate profit.
} 
We next consider which partner for firm $i$ would maximize welfare. Recall that when considering which partner would maximize the increase in joint profit (section 4.1), the choice of the partner affects the joint profit before the transfer (a less efficient partner chosen means smaller joint profit before the transfer). However, when considering which partner would maximize the increase in welfare, welfare before the transfer occurs is not affected by the choice of partner since welfare includes the sum of all firms' operating cost. For this reason, when considering welfare, the choice of a partner is equivalent to the choice of amount of technology transferred. It can be shown that if the licensor is sufficiently inefficient then derivative with respect to $c_{j}$ is initially negative: as we know welfare can decrease with a complete technology transfer when both firms are sufficiently inefficient. A little more insightful is that since the function is convex, then if there is a partner that would increase welfare, then the least efficient partner would increase welfare the most. Specifically, it can be shown that if firm $i$ is sufficiently efficient $\left(c_{i} \approx 0\right)$, then the derivative at $c_{j}=c_{i}$ is positive and so since welfare is convex in $c_{j}$ it is welfare optimal that firm $i$ chooses the least efficient firm to make a complete transfer. When considering private incentives instead, we saw that for joint profit maximization there was an interior solution (proposition 5): the best partner was not too inefficient. Thus, with complete transfers the efficient firms may choose an overly efficient firm as a partner.

\section{Proposition 9: With linear demand, the profit maximizing partner for a sufficiently efficient firm} to make a complete transfer to is more efficient than the welfare maximizing partner.

We bring to a close this subsection by considering the case of a fixed technology transfer. We saw that the joint-profit maximizing choice would be to choose the most efficient firm possible. It turns out that in this case, the welfare calculus yields the same result. The reason is simple. First, a given reduction in aggregate marginal cost has the same effect on consumer surplus independent of the firm receiving the cost reduction. Second, the only effect this change has on aggregate profit is on the licensee's change of profit since the market price after the transfer depends only on aggregate marginal cost (and so is independent of which firm receives the transfer). However, this is the same calculation for maximizing joint profit and so the two questions yield the same answer. 


\subsection{Welfare-improving profitable licensing}

The previous subsection provided conditions for technology transfer to reduce welfare even when such transfers are profitable. The final result though was that, with linear demand, if firm $i$ is sufficiently efficient then a complete transfer raises welfare. The leads to the question of whether this would hold under more general demand and how efficient must firm $i$ must be. Indeed, we can show that if firm $i$ is the most efficient firm, then a complete transfer is always welfare increasing. For this result, we need no condition on demand function (see the appendix for the proof).

Proposition 10. Suppose that the most efficient firm 1 makes a complete transfer to firm $j\left(c_{1}\right.$ $\left.\leq c_{2} \leq \ldots \leq c_{j} \leq \ldots \leq c_{K}\right)$. Then, the social welfare improves.

Thus, a complete technology transfer by the most efficient firm always raises welfare. Actually, from the proof in the appendix, it is clear that a complete technology transfer to the least efficient firm from the most efficient firm achieves the highest social welfare gain (in contrast to the case of a fixed technology transfer when a transfer to the most efficient firm possible achieves the highest social welfare gain). Thus, we can make a weaker statement of Proposition 9 without the linear demand assumption.

Proposition 9': The profit maximizing partner for the most efficient firm to make a complete transfer to is more efficient than the welfare maximizing partner, since the latter is the least efficient firm.

The results here suggest that for complete transfers (or those proportional to the technology gap between the firms), policy makers may want to encourage the dominant firm in an industry to license its superiority to a partner less efficient than the firm would find most profitable. On the other hand, for fixed technology transfers, the dominant firm's incentives would be in line with social incentives. Thus, in considering policy, a critical fact is whether the transfer is independent of the efficient differences. 


\section{Conclusion}

We explore technology transfers (through licensing or joint venture agreements) in a market with firms heterogeneous in cost. We begin by considering the profit maximizing amount of technology to be transferred. We find that with weakly concave demand (which includes linear demand) a small (partial) technology transfer is unprofitable when the receiving firm is sufficiently inefficient, but profitable when the two firms are sufficiently similar. Thus, if only part of the efficiency differences between firms is appropriable (so that the less efficient firm cannot be made as efficient as the superior firm) then we expect to see transfers between efficient firms only. An implication of this result is that a merger between two inefficient firms can be profitable under conditions in which they normally are not profitable (Salant, et al. 1978) if the output decisions remain independent (Kamien and Zang 1990) and the less efficient firm becomes even less efficient. That is, a merger can be profitable by raising a division's cost.

We then turn to examine the case of complete transfers (i.e., the receiving firm becomes as efficient as the licensor). Even though partial transfers can reduce joint profit, we find that under weakly concave demand, any complete technology transfer between firms increases joint profit (that is, licensing complete transfers is profitable) so long as there are at least three firms in the market. Thus, to the extent that the Toyota-GM joint venture was driven by the technology transfer, a sufficient condition for it to have been successful would have been that GM lowered its cost to Toyota's level, which recent events suggest have not occurred. From our results regarding partial transfers, we see that if GM's cost reduction was small enough then their joint profit could well have decreased from the venture. An implication of these results is that an attempted technology transfer that will either be complete or, with some probability, transfers nothing is more profitable to one that transfers only a partial amount with certainty, even if the expected amount of technology transferred is greater in the certainty case.

We then consider which partner a firm would choose to license its technology. Our first result is that with complete transfers the optimal partner is neither too close to the firm in terms of efficiency nor too inefficient. Work by Lieberman and Dhawan (2005) suggests that GM and Ford were equally efficient at that time, while Chrysler was the least efficient (Toyota's discussions with Ford but not Chrysler then is potentially consistent with this). We then consider a transfer of a fixed amount of technology, which corresponds to the case when the firm has made an advance 
on a particular part of the production process (e.g., Toyota's production process). In such a case we find that the firm would engage in a transfer with the most efficient of possible partners, which at the time according to Lieberman and Dhawan (2005), GM was of the three American producers.

As the FTC had to approve the joint venture between Toyota and GM, and more generally competition authorities typically approve licensing agreements or joint ventures, it is natural to give consideration to the welfare implications of technology transfers. We find that contrary to previous results, profitable licensing may have a negative welfare effect: a complete technology transfer between two sufficiently inefficient firms, although profitable, is welfare reducing. Thus, competition authorities should treat with caution licensing or joint venture agreements between inefficient firms despite any innate inclination to foster competition against a firm that dominates the market. On the other hand, unprofitable licensing by a very efficient firm may be welfare improving and so potentially should be encourage despite being unprofitable. Turning to the welfare implications of partner selection we find that if the licensor is the most efficient firm, then a complete technology transfer always raises welfare, and with linear demand there are partial transfers that reduce joint profits and yet raise welfare. Further, for complete transfers a welfare maximizer would want this firm to select a partner that is less efficient than the one that maximizes joint profit. Thus, in this case competition authorities may want to encourage a dominant firm to license or engage in joint production with the least efficient firm possible rather than choosing a more similar partner. 


\section{Appendix}

Proposition 2. With linear demand, the joint profit of firms $k$ and $j$ initially decreases monotonically for $T \in(0, \underline{T})$ and then increases monotonically for $T \in\left(\underline{T}, c_{j}-c_{k}\right]$, if the following condition is satisfied

$$
P(C)-c_{j}<\frac{c_{j}-c_{k}}{K-1} .
$$

This implies that there is a critical value $T^{*}>\underline{T}$, such that the total benefit from the transfer, $\Delta \pi^{T}$, takes negative values for $T \in\left(0, T^{*}\right)$.

Proof. The total benefits from the technology transfer is

$$
\begin{gathered}
\Delta \pi^{T}=\pi_{i}^{T}+\pi_{j}^{T}-\pi_{i}-\pi_{j} \\
=\frac{\left(K^{2}+1\right) T^{2}}{(K+1)^{2}}+\frac{2 T}{K+1}\left[(K-1)\left(P(C)-c_{j}\right)-\left(c_{j}-c_{i}\right)\right] .
\end{gathered}
$$

Let $T^{*}$ be the level of technology such that (4) is zero. Taking the derivative of the above (4), the total benefit from a technology change $T$, with respect to $T$ is

$$
\frac{2\left(K^{2}+1\right)}{(K+1)^{2}} T+\frac{2}{K+1}\left[(K-1)\left(P(C)-c_{j}\right)-\left(c_{j}-c_{i}\right)\right],
$$

which is the same as before when $T=0$. When $-\left(P-c_{i}\right)+K\left(P-c_{j}\right)<0$, the the derivative (A1) takes negative value for small $T$. Equating (5) to zero obtain the worst possible technology transfer $\underline{T}$ :

$$
\underline{T}=-\frac{(K+1)}{\left(K^{2}+1\right)}\left[(K-1)\left(P(C)-c_{j}\right)-\left(c_{j}-c_{i}\right)\right]>0 . / /
$$

Proposition 3: If demand is weakly concave, then

A. when the firms have sufficiently similar costs $\left(c_{j} \approx c_{i}\right)$, a small technology transfer increases joint profit.

$B$. when the less efficient firm is sufficiently inefficient ( $c_{j}$ is sufficiently to close to the market price: $\left.P(C)-c_{j} \approx 0\right)$, a small technology transfer decreases joint profit. 
Proof. From Lemma 2, we know that the sign of $\mathrm{d} \prod / \mathrm{d} T$ depended on

$$
2\left[-\left(P-c_{i}\right)+K\left(P-c_{j}\right)\right]+\left[\left(P-c_{i}\right)^{2}+\left(P-c_{j}\right)^{2}+2\left(P-c_{j}\right)\left(P^{\prime} Q\right)\right] \frac{P^{\prime \prime}}{\left(-P^{\prime}\right)^{2}}
$$

Recall that we found that when demand is linear $\left(P^{\prime \prime}=0\right)$ that only the sign of the first bracketed term matters, that then if the firms are sufficiently similar $\left(c_{j} \approx c_{i}\right)$, then a technology transfer always increases joint profit (i.e., then $\left.P(C)-c_{j}>\left(c_{j}-c_{i}\right) /(K-1)\right)$. On the other hand, when firm $j$ is sufficiently inefficient (so that $P(C)-c_{j} \approx 0$ ), then a small technology transfer decreases joint profit (i.e., then $\left.P(C)-c_{j}<\left(c_{j}-c_{i}\right) /(K-1)\right)$.

The above argument for linear demand extends to the case of weakly concave demand $\left(P^{\prime \prime} \leq 0\right)$. Specifically, if firm $i$ chooses a partner close in technology to itself $\left(c_{j} \approx c_{i}\right)$, then the marginal effect from a transfer positive. To see this, note that the second bracketed term can be re-written as

$$
\left(P-c_{j}\right)\left[\left\{\frac{P-c_{i}}{P-c_{j}}\left(P-c_{i}\right)+P^{\prime} Q\right\}+\left\{P-c_{j}+P^{\prime} Q\right\}\right]
$$

By the first order conditions $P-c_{i}+P^{\prime} Q<0$ and so as $c_{j} \approx c_{i}, \frac{P-c_{i}}{P-c_{j}}\left(P-c_{i}\right)+P^{\prime} Q<0$. On the other hand, as firm $j$ becomes less efficient, $c_{j} \approx P$, the bracketed term becomes positive and the expression becomes negative.//

Proposition 4. Assume interior solutions (no firm chooses zero production). Then, for any pair of firms $i$ and $j$ with $c_{i}<c_{j}$, a complete technology transfer from firm $i$ to firm $j$ is joint profit improving, if $K \geq 3$ and $P^{\prime \prime}(Q) \leq 0$ for all $Q$.

Proof. First note that weakly concave demand implies strategic substitutability. In order to prove the above, we use an artificial economy. This is provided only for the sake of proving the proposition. Let's denote the original equilibrium by "hat". Assume that, originally, $c_{j}$ is exactly the same as the market price $c_{j}=P(\hat{Q})$. We are interested in what happens to firms $i$ and $j$ 's joint 
profit after the complete technology transfer. Before the technology transfer, there is essentially $K-1$ firms only (firm $j$ produces nothing).

$$
P^{\prime}(\hat{Q}) \hat{Q}+(K-1) P(\hat{Q})-\left(\hat{C}-c_{j}\right)=0,
$$

since $c_{j}=P(\hat{Q})$. The original profit is

$$
\pi_{i}=\frac{\left(P(\hat{Q})-c_{i}\right)^{2}}{-P^{\prime}(\hat{Q})} .
$$

After technology transfer, the new equilibrium aggregate output is described by

$$
P^{\prime}(\tilde{Q}) \tilde{Q}+K P(\tilde{Q})-\tilde{C}=0
$$

where $\tilde{C}=\hat{C}-c_{j}+c_{i}$. The two firms' joint profit after the transfer is written as

$$
\pi_{i}+\pi_{j}=2 \frac{\left(P(\tilde{Q})-c_{i}\right)^{2}}{-P^{\prime}(\tilde{Q})} .
$$

Let's consider an artificial procedure to move from $\hat{Q}$ to $\tilde{Q}$. Consider the case where firm $i$ acts as usual by producing $q_{i}=\left(P(Q)-c_{i}\right) /\left(-P^{\prime}(Q)\right)$, while firm $j$ produces only a fraction of firm $i$ 's production, $\alpha q_{i}$, by using firm $i$ 's superior technology $c_{i}, \alpha \in[0,1]$. That is, instead of technology is gradually transferred, we let firm $j$ be a fraction of firm $i$, and increase the fraction $\alpha$. These firms' joint output level is $q(\alpha)=(1+\alpha) q_{i}$, and their joint profit is

$$
\Pi(\alpha)=(1+\alpha) \pi_{i}=\frac{(1+\alpha)\left(P(Q)-c_{i}\right)^{2}}{-P^{\prime}(Q)} .
$$

The following lemma shows that $\Pi(\alpha)$ is increasing in $\alpha$ if $K \geq 3$ and $P^{\prime \prime}(Q) \leq 0$, which for expositional reasons the proof is postponed to the end of the proof.

Lemma A1. Assume strategic substitutability and interior solutions (no firm chooses zero production). In the above artificial economy, at any stage $\alpha \in[0,1]$, the joint profit of firms $i$ and $j$ improves monotonically if and only if the following condition is satisfied for all $\alpha$ :

$$
(K-1-2 \alpha)\left(-P^{\prime}(Q(\alpha))\right)+\left(-P^{\prime \prime}(Q(\alpha))\right)\left(Q(\alpha)-(1+\alpha) q_{i}\right) \geq 0 .
$$

In particular, if $K \geq 3$ and $P^{\prime \prime}(Q) \leq 0$ for all $Q$, the above condition is always satisfied.

Now, we link the artificial market to the "real" market. Let us consider an artificial market in 
stage $\alpha$. The total output level is $Q(\alpha)$, and firms except for $j$ are producing $q_{k}(\alpha)$. Firm $j$ produces $\alpha q_{i}(\alpha)$ at marginal cost $c_{i}$. Let us construct the actual Cournot equilibrium in which each firm produces exactly the same amount as in the artificial economy. In order to do so, we only need to find $c_{j}$ such that firm $j$ optimally produce $q_{j}(\alpha)=\alpha q_{i}(\alpha)$. That is,

$$
\frac{\alpha\left(P(Q(\alpha))-c_{i}\right)}{-P^{\prime}(Q(\alpha))}=\frac{P(Q(\alpha))-c_{j}}{-P^{\prime}(Q(\alpha))},
$$

or

$$
c_{j}(\alpha)=(1-\alpha) P(Q(\alpha))+\alpha c_{i}
$$

Differentiating $c_{j}$ with respect to $\alpha$, we obtain,

$$
c_{j}^{\prime}(\alpha)=c_{i}-P(Q(\alpha))+(1-\alpha) P^{\prime}(Q(\alpha)) \frac{d Q}{d \alpha}<0 .
$$

This together with $c_{j}(0)=c_{j}=P(\hat{Q})$ and $c_{j}(1)=c_{i}$ implies that all $c_{j} \in\left[c_{i}, P(\hat{Q})\right]$ we can find an $\alpha$ $\in[0,1)$ such that $c_{j}=c_{j}(\alpha)$.

The remainder is straightforward. Suppose that $c_{j} \in\left[c_{i}, P(\hat{Q})\right]$. Then, for corresponding $\alpha$ $\left(c_{j}=c_{j}(\alpha)\right)$,

$$
\begin{aligned}
\Pi(\alpha) & =\frac{(1+\alpha)\left(P-c_{i}\right)^{2}}{-P^{\prime}} \\
& =\left(P-c_{i}\right) \times \frac{P-c_{i}}{-P^{\prime}}+\left(P-c_{i}\right) \times \frac{\alpha\left(P-c_{i}\right)}{-P^{\prime}} \\
& \geq\left(P-c_{i}\right) q_{i}(\alpha)+\left(P-c_{j}(\alpha)\right) \times q_{j}(\alpha)=\pi_{i}(\alpha)+\pi_{j}(\alpha) .
\end{aligned}
$$

Since $\Pi(1) \geq \Pi(\alpha)$, we conclude $\Pi(1) \geq \pi_{i}(\alpha)+\pi_{j}(\alpha) . / /$

Lemma A1. Assume strategic substitutability and interior solutions (no firm chooses zero production). In the above artificial economy, at any stage $\alpha \in[0,1]$, the joint profit of firms $i$ and $j$ improves monotonically if and only if the following condition is satisfied for all $\alpha$ :

$$
(K-1-2 \alpha)\left(-P^{\prime}(Q(\alpha))\right)+\left(-P^{\prime \prime}(Q(\alpha))\right)\left(Q(\alpha)-(1+\alpha) q_{i}\right) \geq 0 .
$$

In particular, if $K \geq 3$ and $P(Q) \leq 0$ for all $Q$, the above condition is always satisfied.

Proof. With these firms, equilibrium output level $Q(\alpha)$ is determined by 


$$
\begin{aligned}
Q(\alpha) & =\sum_{k \in K} q_{k} \\
& =\sum_{k \neq i, j} \frac{\left(P(Q)-c_{k}\right)}{-P^{\prime}(Q)}+\frac{(1+\alpha)\left(P(Q)-c_{i}\right)}{-P^{\prime}(Q)} \\
& =\frac{(K-2+1+\alpha) P(Q)-\left(\sum_{k \neq i, j} c_{k}+(1+\alpha) c_{i}\right)}{-P^{\prime}(Q)} \\
& =\frac{(K-1+\alpha) P(Q)-\left(\sum_{k \neq i, j} c_{k}+2 c_{i}+(-1+\alpha) c_{i}\right)}{-P^{\prime}(Q)}
\end{aligned}
$$

Thus, we have

$$
P^{\prime}(Q(\alpha)) Q(\alpha)+K P(Q(\alpha))-\left(\tilde{C}+(1-\alpha)\left(P(Q(\alpha))-c_{i}\right)\right)=0,
$$

where, as before, $\tilde{C}$ is the sum of marginal cost after firm $i$ 's technology is transferred to firm $j$. Totally differentiating the above, we obtain

$$
\frac{d Q}{d \alpha}=\frac{P(Q)-c_{i}}{-P^{\prime \prime} Q-(K+1) P^{\prime}}
$$

This is positive for all $\alpha$, since aggregating strategic substitutability condition obtains $P^{\prime \prime} Q+K P^{\prime}$ $\leq 0$. Then, we have

$$
\begin{aligned}
& \frac{d \Pi}{d \alpha}=\frac{\left(P-c_{i}\right)^{2}}{-P^{\prime}}+\frac{(1+\alpha)\left\{-2\left(P-c_{i}\right)\left(-P^{\prime}\right)^{2}+\left(P-c_{i}\right)^{2} P^{\prime \prime}\right\}}{\left(-P^{\prime}\right)^{2}} \\
& \quad \times \frac{\left(P-c_{i}\right)}{-P^{\prime \prime} Q-(K+1) P^{\prime}} \\
& =\frac{\left(P-c_{i}\right)^{2}}{\left(-P^{\prime}\right)\left(-P^{\prime \prime} Q-(K+1) P^{\prime}\right)} \\
& \times\left[-P^{\prime \prime} Q-(K+1) P^{\prime}-2(1+\alpha)\left(-P^{\prime}\right)+(1+\alpha) P^{\prime \prime} \frac{\left(P-c_{i}\right)}{-P^{\prime}}\right] .
\end{aligned}
$$

By strategic substitutability, the coefficient is positive. Thus, if the contents of the bracket is positive, then $d \prod / d \alpha>0$. Since $q_{i}=\left(P(Q)-c_{i}\right) /-P^{\prime}(Q)$, we have the bracketed term equaling

$$
\begin{aligned}
& =-P^{\prime \prime} Q-(K+1) P^{\prime}-2(1+\alpha)\left(-P^{\prime}\right)+(1+\alpha) P^{\prime \prime} q_{i} \\
& =(K-1-2 \alpha)\left(-P^{\prime}\right)+\left(-P^{\prime \prime}\right)\left(Q-(1+\alpha) q_{i}\right)>0 . / /
\end{aligned}
$$


Proposition 5. With a complete transfer, the joint-profit maximizing partner for a firm is neither too efficient nor too inefficient relative to the firm under weakly concave demand.

Proof: Recall from the main body of the text that the derivative of joint profit with respect to $c_{j}$ is

$$
\frac{\partial \Pi}{\partial c_{j}}=\frac{-2\left(P\left(Q\left(C^{i j}\right)\right)-c_{i}\right)}{\left[P^{\prime}\left(Q\left(C^{i j}\right)\right)\right]^{2}} \frac{d Q}{d c_{j}}\left[2 P^{\prime}+P^{\prime \prime} q_{i}\right] P^{\prime}+\left[\frac{-2\left(P(Q)-c_{j}\right)}{P^{\prime}(Q)}\right]
$$

First, if firm $j$ is sufficiently inefficient $\left(c_{j} \rightarrow P\right)$, then the second term goes to zero: a very inefficient firm is never the profit maximizing partner. Next, if firm $j$ is sufficiently efficient $\left(c_{j} \rightarrow\right.$ $c_{i}$ ), the derivative must be positive. This is because we know that complete transfers are profit improving with weakly concave demand and that the change in profit when $c_{j}=c_{i}$ is zero.//

Proposition 6. With a fixed amount of technology to be transferred, the firm chooses the closest partner possible under strategic substitutability.

Proof. The effect on the joint profit for the licensor and licensee from the transfer is:

$$
\Delta \pi^{T}=\pi_{i}^{T}+\pi_{j}^{T}-\pi_{i}-\pi_{j}=\frac{\left(P\left(Q\left(C^{T}\right)-c_{i}\right)^{2}\right.}{-P^{\prime}\left(Q\left(C^{T}\right)\right)}+\frac{\left(P\left(Q\left(C^{T}\right)\right)-c_{j}+T\right)^{2}}{-P^{\prime}\left(Q\left(C^{T}\right)\right)}-\frac{\left(P(Q)-c_{i}\right)^{2}}{-P^{\prime}(Q)}-\frac{\left(P(Q)-c_{j}\right)^{2}}{-P^{\prime}(Q)},
$$

The critical thing to note in this case is that for the licensor it does not matter which firm received the transfer since the transfer has the same effect on aggregate marginal cost and so on the resulting price. Taking the derivative with respect to $c_{j}$ we obtain:

$$
\frac{\partial \Delta \pi^{T}}{\partial c_{j}}=\frac{-2\left(P\left(Q\left(C^{T}\right)\right)-c_{j}+T\right)}{-P^{\prime}\left(Q\left(C^{T}\right)\right)}+\frac{2\left(P(Q)-c_{j}\right)}{-P^{\prime}(Q)}=-2\left(q_{j}^{T}\left(C^{T}\right)-q_{j}(C)\right) .
$$

Next, note that a firm's output is increasing in the amount of technology received: 


$$
\begin{aligned}
\frac{\partial}{\partial T} \frac{2\left(P\left(Q\left(C^{T}\right)\right)-c_{j}+T\right)}{-P^{\prime}\left(Q\left(C^{T}\right)\right)} & =\frac{-2}{\left[P^{\prime}(Q)\right]^{2}}\left[\left(P^{\prime}(Q) \frac{d Q}{d T}+1\right) P^{\prime}(Q)-P^{\prime \prime}(Q) \frac{d Q}{d T}\left(P(Q)-c_{j}+T\right)\right] \\
& =\frac{-2}{P^{\prime}}\left[\left(P^{\prime} \frac{d Q}{d T}+1\right)-P^{\prime \prime} \frac{d Q}{d T} \frac{\left.P-c_{j}+T\right)}{P^{\prime}}\right] \\
& =\frac{-2}{P^{\prime}}\left[\left(\frac{P^{\prime}}{-P^{\prime \prime} Q-(K+1) P^{\prime}}+1\right)+\frac{P^{\prime \prime}}{-P^{\prime \prime} Q-(K+1) P^{\prime}} q_{j}^{T}\right] \\
& =\frac{-2}{P^{\prime}}\left[1-\frac{-P^{\prime \prime} q_{j}^{T}-P^{\prime}}{-P^{\prime \prime} Q-(K+1) P^{\prime}}\right]>0
\end{aligned}
$$

because $-P^{\prime \prime} q_{j}^{T}-P^{\prime}<-P^{\prime \prime} Q-(K+1) P^{\prime}$ by strategic substitutability. Thus, $-2\left(q_{j}^{T}\left(C^{T}\right)-q_{j}(C)\right)<$ 0. That is, as $c_{j}$ increases joint profit decreases the most efficient firm is the joint profit maximizing licensee.//

Lemma 3'. With linear demand social welfare decreases when firm i makes a technology transfer to firm $j$ if

$$
-\frac{2+K+3 C+2 C K}{2(K+1)^{2}}+c_{k}>0 .
$$

A sufficient condition for this is that firm j has marginal cost $\left(c_{j}\right)$ greater than $\frac{1}{2 K}+C$

Proof. Social welfare is written as gross consumers' benefit $C B$ minus total production cost $T C$. Gross consumers' benefit is written as

$$
\begin{aligned}
C B & =\frac{1}{2}(1+P(C)) \times Q(C) \\
& =\frac{1}{2}\left(1+\frac{1}{K+1}+\frac{\sum_{i=1}^{K} c_{i}}{K+1}\right) \times\left(\frac{K}{K+1}-\frac{\sum_{i=1}^{K} c_{i}}{K+1}\right) \\
& =\frac{1}{2}\left(\frac{K+2}{K+1}+\frac{\sum_{i=1}^{K} c_{i}}{K+1}\right) \times\left(\frac{K}{K+1}-\frac{\sum_{i=1}^{K} c_{i}}{K+1}\right) \\
& =\frac{1}{2}\left(\frac{K(K+2)}{(K+1)^{2}}-\frac{2 \sum_{i=1}^{K} c_{i}}{(K+1)^{2}}-\frac{\left(\sum_{i=1}^{K} c_{i}\right)^{2}}{(K+1)^{2}}\right) .
\end{aligned}
$$


This is a decreasing in $c_{i}$ for all $i=1, \ldots, K$. Total production cost is written as

$$
\begin{aligned}
T C & =\sum_{i=1}^{K} c_{i} \times q_{i} \\
& =\sum_{i=1}^{K} c_{i} \times\left(P(C)-c_{i}\right) \\
& =\sum_{i=1}^{K} c_{i} \times\left(\frac{1}{K+1}+\frac{\sum_{i=1}^{K} c_{i}}{K+1}-c_{i}\right) \\
& =\frac{\sum_{i=1}^{K} c_{i}}{K+1}+\frac{\left(\sum_{i=1}^{K} c_{i}\right)^{2}}{K+1}-\sum_{i=1}^{K} c_{i}^{2}
\end{aligned}
$$

Thus, the social welfare is written as

$$
\begin{aligned}
W= & C B-T C \\
= & \frac{1}{2}\left(\frac{K(K+2)}{(K+1)^{2}}-\frac{2 \sum_{i=1}^{K} c_{i}}{(K+1)^{2}}-\frac{\left(\sum_{i=1}^{K} c_{i}\right)^{2}}{(K+1)^{2}}\right)-\left(\frac{\sum_{i=1}^{K} c_{i}}{K+1}+\frac{\left(\sum_{i=1}^{K} c_{i}\right)^{2}}{K+1}-\sum_{i=1}^{K} c_{i}^{2}\right) \\
= & \frac{K(K+2)}{2(K+1)^{2}}-\frac{(2 K+4) \sum_{i=1}^{K} c_{i}}{2(K+1)^{2}}-\frac{(2 K+3)\left(\sum_{i=1}^{K} c_{i}\right)^{2}}{2(K+1)^{2}}+\sum_{i=1}^{K} c_{i}^{2}
\end{aligned}
$$

Differentiating the above with respect to $c_{k}$ produces,

$$
\begin{aligned}
\frac{\partial W}{\partial c_{k}} & =-\frac{(2 K+4)}{2(K+1)^{2}}-\frac{2(2 K+3)\left(\sum_{i=1}^{K} c_{i}\right)}{2(K+1)^{2}}+2 c_{k} \\
& =-\frac{4+2 K+6 C+4 C K}{2(K+1)^{2}}+2 c_{k} .
\end{aligned}
$$

Note that

$$
\frac{2 K+3}{2(K+1)^{2}}<\frac{2 K+4}{2(K+1)^{2}}=\frac{K+2}{K^{2}+2 K+1}<\frac{1}{K}
$$

Thus, if $c_{k} \geq \frac{1}{2 K}+\frac{C}{K}$ holds, we have necessarily $\frac{\partial W}{\partial c_{k}}>0$. In other words, if firm $k$ 's cost goes down by a small amount, then the social welfare declines when $c_{k} \geq \frac{1}{2 K}+\frac{C}{K}$ is satisfied.//

Proposition 8: With linear demand, if a small technology transfer reduces joint profit, then it 
reduces welfare when the transferring firm has above average cost technology and $K>2$.

Proof. A small technology transfer reduces joint profit when

$$
c_{j}>\frac{(1+C)(K-1)}{K(K+1)}+\frac{c_{i}}{K} .
$$

If firm $i$ has above average cost $\left(c_{i}>C / K\right)$, then

$$
c_{j}>\frac{(1+C)(K-1)}{K(K+1)}+\frac{C}{K^{2}} .
$$

Since

$$
\frac{(1+C)(K-1)}{K(K+1)}+\frac{C}{K^{2}}-\frac{2+K+3 C+2 C K}{2(K+1)^{2}}=\frac{\left(K^{2}-2 K-2\right)(K-C)}{2 K^{2}(K+1)^{2}}
$$

Then,

$$
c_{j}>\frac{(1+C)(K-1)}{K(K+1)}+\frac{C}{K}>\frac{2+K+3 C+2 C K}{2(K+1)^{2}}
$$

so long as $K \geq 3$ since for an interior solution we must have that $K>C$.//

Proposition 10. Suppose that the most efficient firm makes a complete transfer to firm $j\left(c_{1} \leq\right.$ $\left.c_{2} \leq \ldots \leq c_{j} \leq \ldots \leq c_{K}\right)$. Then, the social welfare improves.

Proof. First note that if the total output increases, then each firm's output level shrinks other things equal:

$$
q_{k}(Q)=\frac{P(Q)-c_{k}}{-P^{\prime}(Q)} .
$$

Now, by Lemma 1, if firm $j$ 's marginal cost $c_{j}$ improves to $c_{l}$, then the total output increases. Let's denote the original equilibrium by "hat", and the new equilibrium by "tilde". Then, we have $\hat{Q}<\tilde{Q}$ and $\hat{q}_{k}>\tilde{q}_{k}$ for all $k \neq j$. Since $Q=\sum_{k=1}^{K} q_{k}$, we necessarily have $\hat{q}_{j}<\tilde{q}_{j}$ and 
$\tilde{q}_{j}-\hat{q}_{j}>\tilde{Q}-\hat{Q}$. The social welfare is written as

$$
\begin{aligned}
S W & =(\text { total benefit })-(\text { total cost }) \\
& =\int_{0}^{Q} P\left(Q^{\prime}\right) d Q^{\prime}-\sum_{k=1}^{K} c_{k} q_{k} .
\end{aligned}
$$

Therefore, we have

$$
\begin{aligned}
\widetilde{S W} & =\int_{0}^{\tilde{Q}} P\left(Q^{\prime}\right) d Q^{\prime}-\sum_{k=1}^{K} c_{k} \tilde{q}_{k} \\
& =\int_{0}^{\hat{Q}} P\left(Q^{\prime}\right) d Q^{\prime}+\int_{\hat{Q}}^{\tilde{Q}} P\left(Q^{\prime}\right) d Q^{\prime}-\sum_{k \neq j} c_{k} \tilde{q}_{k}-c_{1} \tilde{q}_{j} \\
& =\int_{0}^{\hat{Q}} P\left(Q^{\prime}\right) d Q^{\prime}+\int_{\hat{Q}}^{\tilde{Q}} P\left(Q^{\prime}\right) d Q^{\prime}-\sum_{k \neq j} c_{k} \tilde{q}_{k}-c_{1}(\tilde{Q}-\hat{Q})-c_{1}\left(\tilde{q}_{j}-(\tilde{Q}-\hat{Q})\right) \\
& =\int_{0}^{\hat{Q}} P\left(Q^{\prime}\right) d Q^{\prime}-\sum_{k \neq j} c_{k} \tilde{q}_{k}-c_{1}\left(\tilde{q}_{j}-(\tilde{Q}-\hat{Q})\right)+\int_{\hat{Q}}^{\tilde{Q}} P\left(Q^{\prime}\right) d Q^{\prime}-c_{1}(\tilde{Q}-\hat{Q}) .
\end{aligned}
$$

The last two terms are obviously positive, since $P(\tilde{Q})>c_{1}$. Thus, we concentrate on the first three terms. The first three terms minus $\widehat{S W}$ is

$$
\begin{aligned}
& =\int_{0}^{\hat{Q}} P\left(Q^{\prime}\right) d Q^{\prime}-\sum_{k \neq j} c_{k} \tilde{q}_{k}-c_{1}\left(\tilde{q}_{j}-(\tilde{Q}-\hat{Q})\right)-\int_{0}^{\hat{Q}} P\left(Q^{\prime}\right) d Q^{\prime}+\sum_{k=1}^{K} c_{k} \hat{q}_{k} \\
& =\sum_{k=1}^{K} c_{k} \hat{q}_{k}-\sum_{k \neq j} c_{k} \tilde{q}_{k}-c_{1}\left(\tilde{q}_{j}-(\tilde{Q}-\hat{Q})\right) \\
& =\sum_{k \neq j} c_{k}\left(\hat{q}_{k}-\tilde{q}_{k}\right)+c_{j} \hat{q}_{j}-c_{1}\left(\tilde{q}_{j}-\sum_{k=1}^{K}\left(\tilde{q}_{k}-\hat{q}_{k}\right)\right) \\
& =\sum_{k \neq j} c_{k}\left(\hat{q}_{k}-\tilde{q}_{k}\right)+c_{j} \hat{q}_{j}-c_{1} \hat{q}_{j}+\sum_{k \neq j} c_{1}\left(\tilde{q}_{k}-\hat{q}_{k}\right) \\
& =\sum_{k \neq j}\left(c_{k}-c_{1}\right)\left(\hat{q}_{k}-\tilde{q}_{k}\right)+\left(c_{j}-c_{1}\right) \hat{q}_{j}>0 .
\end{aligned}
$$

Hence, we conclude $\widetilde{S W}>\widehat{S W} . / /$ 


\section{References}

Astebro, Thomas (2002) 'Non-Capital investment costs and the adoption of CAD and CNC in the U.S. metalworking industries,' RAND Journal of Economics, 33, 672-688.

Baye, M., Crocker, K. and Ju, J., 1996, "Divisionalization, Franchising, and Divestiture Incentives in Oligopoly," American Economic Review 86(1), 223-236.

Choi, J.P, 2002, "A Dynamic Analysis of Licensing: The "Boomerang" Effect and Grant-Back Clauses," International Economic Review 43(3), 803-829.

Cohen, S., 1990, "Marrying For Money, Not Love: Japan and American Steel Get Together," Associated Press, December 15.

Creane, A., and H. Konishi, 2009, "The Unilateral Incentives for Technology Transfers: Predation (and Deterrence) by Proxy,” International Journal of Industrial Organization, Vol. 27(3), May, pp. 379-389.

Farrell, J. and C. Shapiro, 2008, "How Strong Are Weak Patents?” American Economic Review, 98(4): 1347-1369.

Faulí-Oller, R. and Sandonís, 2002, Welfare reducing licensing, Games and Economic Behavior, 2002, vol. 41, 192-205

Fenton, K.M., 2005, “GM/Toyota: Twenty Years Later,” Antitrust Law Journal, 72, 1013-1028.

Giebe T, and E. Wolfstetter, 2008, License auctions with royalty contracts for (winners and) losers, Games and Economic Behavior 63(1), 91-106.

Hernandez-Murillo, R., and G. Llobet, 2006, "Patent licensing revisited: Heterogeneous firms and product differentiation," International Journal of Industrial Organization, 24(1): $149-175$.

Inkpen, A.C., 2000, "Learning through joint ventures: a framework of knowledge acquisition," Journal of Management Studies, 37(7), November, 1019-1043.

Lieberman, M. and R. Dhawan (2005), "Assessing the resource base of Japanese and U.S. auto producers: A stochastic frontier production function approach, Management Science 51(7): 1060-75

Kamien, M.I., Oren, S.S., Tauman, Y.,1992. Optimal licensing of cost-reducing Innovation. Journal of Mathematical Economics 21, 483-508. 
Kamien, M. and Zang, I., 1990, “The Limits of Monopolization through Acquisition,” Quarterly Journal of Economics, 105(2): 465-499.

Katz, M.L., and C. Shapiro, 1985, “On licensing innovations,” Rand Journal of Economics, 16(4), 504-520.

Katz, M.L., and C. Shapiro, 1986, "How to license intangible property," Quarterly Journal of Economics 101, 567-590

Kogut, B., 1988, “Joint Ventures: Theoretical and Empirical Perspectives,” Strategic Management Journal, 9, 319-332.

Lahiri, S., and Y. Ono, 1988. Helping minor firms reduces welfare, The Economic Journal 98(393), 1199-1202.

Levin, D.P., 1992, "Ford to Take 50\% Share in Mazda Plant," The New York Times, D5, column 4, April 16.

Rockett, K.E., 1990, “Choosing the Competition and Patent Licensing” The Rand Journal of Economics, 21(1), 161-171.

Rockett, K., 1991, “The Quality of Licensed Technology,” International Journal of Industrial Organization, 8, 559-574.

Roehl, T.W., and J.F. Truitt, 1987, “Stormy Open Marriages are Better: Evidence From US, Japanese and French Cooperative Ventures in Commercial Aircraft," Columbia Journal of World Business, 22(2), Summer, 87-95.

Salant, S., Switzer, S., and R. Reynolds, 1983 "Losses Due to Merger: The Effects of an Exogenous Change in Industry Structure on Cournot-Nash Equilibrium," Quarterly Journal of Economics, 48, 185-200.

Sen, D. and Y. Tauman, 2007, "General Licensing Schemes for a Cost-Reducing Innovation," Games and Economic Behavior 59(1): 163-86

Shapiro, C., 1985, Patent licensing and R\&D rivalry, American Economic Review, 75(2), 25-30.

Washington Post, 1980, "Ford Toyota Plan to Resume Talks Within Month," Business \& Finance, September 9, p. E4. 